\title{
Televizyon İzleyicisi Kimdir? Kavramsal Bir Tartıșma
}

\author{
KUMRU BERFIN EMRE ÇETIN ${ }^{\star}$
}

\begin{abstract}
ÖZ
Televizyon çalışmaları açısından "izleyici” muğlak ve tarif edilmesi güç bir kavramdır. İletişim alanı içindeki farklı epistemolojik yönelimler, iletişim süreçlerini olduğu kadar izleyiciyi de farklı biçimlerde tarif ederler. Temelde izleyicinin kim olduğu sorusunun yanıtını belirleyen, izleme davranışının nasıl anlaşıldığıdır. İzleme pratikleri gündelik hayat içerisindeki sosyal etkileşimle belirlenir. Bu bağlamda, teknolojik değişimlerin ortaya çıkardığı farklı sosyal etkileşim biçimleri televizyon izleyiciliği pratiğini de biçimlendirmiştir. Bu makalede televizyon çalışmaları alanında izleyici kavramının geçirdiği dönüşüm ele alınmakta, teknolojik yeniliklerle birlikte izleyicilik pratiklerinin değişimi ve bunun televizyon çalışmaları için ne anlama geldiği tartış1lmaktadır.
\end{abstract}

Anahtar sözcükler: Televizyon, izleyici, izleyici araştırmaları, yakınsama, fragmanlaşma

$\mathrm{T}$

ürkiye'de medya çalışmaları içerisinde izleyici araştırmalarının ihmal edilmiş bir alan olduğu söylenebilir ${ }^{1}$. Bunun çeşitli nedenleri olmakla birlikte, Türkiye'de iletişim alanının sosyolojiden ziyade siyaset bilimine yakın bir biçimde gelişmesinin medya çalışmaları içinde “izleyici” nin görünmezleşmesinde önemli payı vardır. Kurumlara ve yapılara yapılan vurgu, onları var eden ve onlarla sürekli ilişki halinde olan öznelerin görmezden gelinmesi sonucunu doğurmuştur. Diğer yandan, izleyici araştırmalarına göreli olarak geç yönelme hali yalnızca Türkiye'ye özgü bir durum değildir. Etki araştırmaları bir kenara bırakılacak olursa, izleyicinin medya araştırmaları içinde saygın bir konum kazanması 1980'lerin sonunu bulur. Bunun önemli nedenlerinden biri, medya

\footnotetext{
* Dr., Hacettepe Üniversitesi, Radyo, Televizyon ve Sinema Bölümü/ANKARA E-posta: berfin@hacettepe.edu.tr

1 Bu konuda yapılmış çalı̧̧malar için bkz. Binark (1995), Batmaz ve Aksoy (1995), Özer (2005), Türkoğlu (2010), Gülnar ve Balcı (2010), Özçetin (2010), Özsoy (2011), Arun (2015).
} 
ürünlerini tüketmekle onları onaylamak arasında kurulan varsayımsal bağdır. Başka bir ifadeyle, izleyicinin belirli bir programı izlemesinin, o programda açık ve örtük olarak ifade edilen düşünceleri ve dünya görüşünü benimsemesi anlamına geldiği kabulüdür. Bu tutum ilk bakışta köktenci bir eleştiriyi içeriyor gibi görünse de, esasen anlamlandırma sürecini izleme etkinliğine indirgemesi bakımından "davranış̧ı" bir yönelimi takip eder. Şüphesiz, televizyon izlemek her koşulda bir tür seçim yapmak anlamına gelir. Ancak televizyon izlemeyi uyumaya veya bir programı diğerine yeğlemek, izlenen programın izleyici tarafindan bütünüyle benimsendiği anlamına gelmez. Özetle, "ne" sorusu "nası" ve "neden" sorularını ikame etmez. İzleyici araştırmaları da esasen izleme ve anlamlandırma süreçlerindeki "neden" ve "nasıl" sorularıly ilgilenir. Başka bir ifadeyle, izleyici araştırmaları açısından izleme davranışının ortaya çıkması yalnızca bir sonuç değil, aynı zamanda bir başlangıç noktasıdır.

İzlemenin nasıl gerçekleştiği, hangi gündelik pratiklerin içine yerleştiği, hangi anlamlandırma sürecine eklemlendiği ve başka ne tür etkinliklerle ilişkilendiği soruları izleme davranışına eşlik eder veya onu takip eder. Bu bakımdan televizyon izleyiciliği sabitlenmiş, durağan bir konumdan ziyade, dinamik, toplumsal ve tarihsel bir pratiğe karşılık gelir. İzleyici araştırmaları da bu dinamik sosyo-tarihsel bağlam içerisine yerleşen özneyi tanımlamaya çalı̧̧ı. "İzleyici" olarak adlandırılan bu özne birçok toplumsal kimliğin katmanlaşmış ve izleme davranı̧̧ı çerçevesinde yeniden tanımlanmış haline denk düşer. Bu makalenin amacı, televizyon çalışmaları alanında izleyici kavramının geçirdiği dönüşümün izini sürmek ve izleyici araştırmalarının güncel çalışmalar açısından taş1dığı önemi ortaya koymaktır. Makalede öncelikle televizyon çalışmaları içinde izleyici kavramının nasıl ele alındığına bakılacak, izleyen bölümde ise yeni teknolojilerle birlikte değişen izleyicinin televizyon çalışmaları açısından ne anlam ifade ettiğgi tartı̧̧lacaktır.

\section{1. Üçüncü Bileşen Olarak İzleyici}

İletişim sürecini modelleyen ilk araştırmalar basitçe gönderen, mesaj ve alıcı üçlüsünü tarif ederek yola çıkarlar (McQuail ve Windahl 2010). İletişimin disiplinlerarası bir alan olarak "özerkliğe" kavuşmasıyla birlikte bu üçlü tarif üretici, metin, izleyici gibi farklı biçimlerde tarif edilegelir ve kimi çalışmaların bu üçlüye iletişim sürecinin gerçekleştiği bağlamı da eklemesiyle iletişim süreçleri farklı soyutlama düzeylerinde tartışılır. Bağlamı daha geniş bir soyutlama düzeyi olarak bir kenara koyacak olursak, alıcı/izleyici iletişim alanında en basite indirgenen, dolayısıyla da araştırmacıların dikkatini bir tüketici olmanın dışında en az çeken bileşendir. Nightingale ve Ross'a göre, medya çalışmaları içinde izleyici kimi zaman bir grup olarak insanlara kimi zaman da tek tek bireylere karşl1ık gelir (2003: 4). İzleyici kelimesi aynı zamanda altkültürler, 
fan grupları, etnik ve dinsel gruplar gibi aralarında sosyo-kültürel bir bağ olan grupları tarif etmek için de kullanılagelmiştir. Bu sosyo-kültürel bağla oluşmuş ortak dağarcık, izleyicinin aynı medya metinlerini belirli örüntüler çerçevesinde yorumlamasını sağlar. Başka bir ifadeyle izleyicinin sosyo-kültürel kimliği izleyicinin hem belirli medya ürünlerine yönelmesine neden olur hem de o ürünleri belirli biçimlerde tüketmesi anlamına gelir. Dolayısıyla izleyici kavramını bireysel özellikler kadar bireylerin sosyo-kültürel kimlikleri bağlamında da düşünmek gerekir. Fiske ve Hartley'e göre, izleyici, öyle olmasına karşın, televizyonun karşısındayken kendini televizyon izleyen bir birey veya o programı izleyen kitlenin bir parçası olarak görmez (2003: 89). Zira televizyon izleme pratiği genellikle ev içinde gerçekleştiği için izleyiciler ailenin bir parçasıdırlar. Dolayısıyla izleyicilik konumu genellikle aile bağlamı içine yerleşmiş, eviçi ve gündelik bir konumdur (Silverstone 1994; Fiske ve Hartley 2003).

Medya çalışmalarında izleyicinin iletişim sürecinin aktif bir parçası olarak görülmesi, bilinen ifadeyle izleyicinin medya ile ne yaptığ1 sorusunun önem kazanması, televizyon söz konusu olduğunda göreli olarak geç bir döneme denk gelir. Eleştirel paradigmanın karşısına aldığı etki araştırmalarında izleyici, medya ürünlerine ve mesajlarına amaçlanan doğrultuda tepki veren, kabullenici, yönlendirilmeye, etkiye açık bir bileşen olarak kavranır (Katz ve Lazarsfeld 1955). İzleyiciye pedagojik tarzda yaklaşarak onu bir nevi "çocuklaştıran" etki araştırmaları, iletişimi yukarıdan aşağıya doğru etki eden dikey bir bakışla tanımlar. Medyanın gücüne ve etkilerinin yaygınlığına duyulan inanç, izleyiciyi medya karşısında güdülebilmekten öte bir potansiyel taşımayan takipçiler olarak konumlandırır. Medya ürününü tüketmekle onu onaylamayı özdeş kabul eden yaklaşımlar, izleyicinin medya veya popüler kültür karşısındaki konumunu izleme/tüketme davranışına indirgerler ve "nasıl" sorusunu geri plana iterler. Bu aynı zamanda, sosyolojik olarak mikro süreçleri, makro süreçlere indirgeyen, gündelik hayata iktidarın bir gölgesi, bir tür kopyası olarak yaklaşan bir yaklaşımı da ifade eder. İzleyici sabun köpüğü dizilere rağbet ettiğine göre, o dizilerdeki tahakküm ilişkilerini onaylamakta, onlara rıza göstermektedir. İzleyicinin medya karşısındaki konumunu küçümseyen bir başka yaklaşım ise, popüler kültürü bir tür "afyon" olarak değerlendirir; izleyici de günlük sıkıntılarını, toplumsal eşitsizliğin yarattığı huzursuzluklarını popüler kültür aracılığıyla unutan bir tür gönüllü-bağımlıdır. Bu nedenle izleyicinin etki-tepki ikiliğinin ötesinde ete kemiğe bürünebilen, belirli bir bağlam içinde kendisini var eden toplumsal bir varlık olduğu fikri, medya çalışmalarında ciddi bir paradigma değişimini de ifade eder. Kimi araştırmacıların "Kullanımlar ve Doyumlar” yaklaşımını (Blumler ve Katz 1974), kimilerinin kültürel çalışmalar ekolünün izleyici araştırmalarını (Hall 1980; Morley 1980, 1992; Ang 1985) başlangiç noktası olarak kabul ettiği bu paradigma değişimi, medya çalışmala- 
rında izleyici araştırmaları veya alımlama çalışmaları olarak adlandırılan bir alt çalışma alanının da doğuşuna neden olmuştur (Ruddock 2001).

Hem "Kullanımlar ve Doyumlar" yaklaşımı hem de kültürel çalışmalar izleyiciyi medya ürününe yönelirken farklı amaç ve yönelimleri olan hem de o ürünü farklı biçimlerde anlamlandırabilen birer özne olarak kavrarlar. Elbette iki yaklaşımın "özne" anlayışının birbirinden oldukça farklı olduğunu vurgulamak gerekir. "Kullanımlar ve Doyumlar" yaklaşımının izleyicisi kendi gereksinimlerinin farkında olan ve medyayı gereksinimleri doğrultusunda kullanan psiko-sosyal bir varlık iken, kültürel çalışmaların izleyicisi toplumsal anlamları medya aracıllğıyla yeniden inşa eden politik bir öznedir. Bu nedenle medya ile izleyicinin ilişkilenmesi sırasında ortaya çıkan, politik bir mücadele alanıdır. Aslında kültürel çalışmaların yaslandığı anlayış, aynı zamanda karşıt bir anlayışa da kapı aralar. Buna göre, sosyolojik bir kategori olarak izleyicilik mümkün değildir. Medyanın gücüne duyulan yaygın inancın, medya çalışmaları açısından etki araştırmaları dışında da sonuçları olmuştur. Örneğin, izleme süreçlerine odaklanmayı öneren Fiske (1987), izleyiciye ampirik olarak ulaşmanın mümkün olmadığını savunur. Zira izleyicilik durumsaldır, toplumsal cinsiyet, sınıf, etnisite gibi üst üste binerek özneyi inşa eden kimliklerle eş tutulması mümkün değildir. Bu nedenle de "izleyici” aslında kavramsal olarak boşgösterendir. Ancak tüketici gibi analitik bir kavramsallaştırmaya başvuruyorsak, benzer bir akıl yürütmeyle izleyici de kavramsal olarak "mümkündür". İzleyici kavramının kurumsal yapılar tarafından nasıl ele alındığını inceleyen Ang'e göre de izleyici sosyolojik bir varlıktan ziyade söylemsel bir inşadır. Kurumsal açıdan izleyici ancak hayali bir varlık olarak mevcuttur ve kurumların çıkarlarını yansıtacak biçimde kavramsallaştırılır (Ang 1991: 2). İzleme ölçümleri yapan ticari kuruluşlar, radyo ve televizyon yayıncllığını düzenleyen kurumlar, televizyon kanalları ve radyo istasyonları, farklı saiklerle de olsa, izleyicinin ölçülebilir, öngörülebilir ve yönlendirilebilirliğine vurgu yaparlar. Elbette ülkelerin yayıncıllk geleneğine göre farklılık gösterebilen, başka bir ifadeyle coğrafi ve kültürel olarak farklılaşan yaklaşımlar, izleme ölçümlerinde, yayınc1lık piyasasını düzenleyen metinlerde ve sunucuların "Sevgili izleyiciler" diyerek başlayan konuşmalarında kristalleşerek kime izleyici dendiğini yeniden tarif ederler. Bu noktada, üç farklı kurumsal yapının, izleme ölçümleri yapan ticari kuruluşlarının (1), RTÜK gibi yayıncıllğ̆ı düzenleyen ve denetleyen kurumların (2) ve radyo ve televizyon istasyonlarının (3), izleyiciyi söylemsel olarak inşa ederken hangi noktalarda farklılaştı̆̆ına odaklanmak gerekir. İzleme ölçümlerinin geçerliliği ve güvenilirliği, medya çalışmaları açısından şüphesiz uzun ve meşakkatli bir tartışmayı hak eden bir konudur. Ticari saiklere hizmet etmesi nedeniyle genel olarak yeterince ele alınmayan bu mev$\mathrm{zu}$, aslında izleme ölçümleri yapan kuruluşların, televizyon kanallarına veri 
raporları halinde sunduğu "izleyici”nin nasıl kavrandığı konusunda da fikir verir. Başka bir ifadeyle, izleme ölçümleri yapan kuruluşların varlık sebebi olan “izleyici”yi kavramsal olarak problemli hale getiren, bu kuruluşlarla, televizyon kanallarının ve reklam veren ticari kuruluşların çıkar ortaklığı olduğu kadar, izleme ölçümlerinin geçerliliği ve güvenilirliği sorununun basit bir ölçme değerlendirme hatası olarak görülemeyeceği gerçeğidir. Evlerine ölçüm aleti yerleştirilen, izleme günlüklerini kullanan, kumandanın tuşlarına, televizyonun açma kapama düğmesine basan, satın alma gücüne göre çeşitli gruplara ayrılmış, televizyon izleyicileri arasından seçilen bir grup olmanın ötesinde, izleme ölçümlerine katılan izleyiciler, aslında birer tüketim birimi olarak kodlanmışlardır. Televizyon izleme, satın alma davranışını çözümleyebilmek için bir araç olarak kullanılır, bu açıdan da izleyici gelir grubu ve izlediği program dışında kurmaca bir öznedir. Düzenleyici kurumlar açısından bakıldığında ise izleyicinin, toplumsal uylaşımları temsil eden televizyonun kötü etkilerinden korunması icap edebilecek bireyler fikrinin geçerli olduğunu, özellikle yaş grubu açısından programlarla uygunluk/uygunsuzluk ilişkisi içinde tanımlandığını görürüz. Düzenleyici ve denetleyici kurumlar, genellikle izleyiciyi hakları bakımından yayıncılık piyasasının olumsuz etkilerine karşı koruyacak bir aracı kurum, "kamu" kurumu olarak işledikleri söylemiyle öne çıkarlar. Bu kurumlarda izleyiciye yönelik korumacı ve pedagojik söylemlerin belirgin olduğunu söylemek mümkündür. Özel televizyon yayıncilı̆ı açısından bakıldığında ise, izleyiciyi aynı anda aynı içeriği tüketen ulusal bir birim olarak tanımlayan kamu yayıncılığından farklı olarak (Scannell 1989), izleyici baştan çıkarılacak, mümkün olduğunca süreğen bir ilişki içine çağırılacak, hem programı hem de reklamı yapılan ürünleri "satın alacak" bir "tüketici”dir. İzleyicilere gerektiğinde yurttaşlar, bayanlar ve baylar, kadınlar, çocuklar olarak, gerektiğinde ise "izleyiciler" torba adlandırmasıla seslenen televizyon programları "izleyici” yi söylemsel olarak inşa ederken izleme ölçümü yapan ticari kuruluşlardan ve düzenleyici ve denetleyici kurumlardan hayli belirsiz, daha doğru ifadeyle bağlama göre değişen, bir tarz tutturur. Günümüzde programların akış1 içerisine sızan "ürün tanıtımları" ve dizilerdeki ürün yerleştirmeler, izleyiciyi inşa eden söylemlerin anlık olarak değişebilen konumuna işaret ederler.

Silverstone, izleyiciyi kuşatan zaman ve uzamların farklılığına işaret eder (1994: 132-133). İzleyici ev içi uzamda, ulusal uzamda, yayıncılık uzamında ve biyografik, gündelik, programlanmış, kendiliğinden ve benzeri zamanlarda düşünüldüğünde farklı biçimlerde tarif edilecektir. Silverstone, izleyici araştırmalarının bu farklılıkları yeterince göz önünde bulundurmadığı için çeşitli metodolojik güçlüklerle karşılaştı̆̆ını vurgular. Bu nedenle izleyiciler katı bir biçimde tarif edilen toplumsal grupların birer üyesi veya kendinden menkul bireyler olarak değil, çeşitli gündelik pratiklerin ve söylemlerin içerisinde düşünülmelidir (1994: 133). Zira televizyon izleme pratiği başka gündelik pra- 
tiklerin ve rutinin eşlik ettiği karmaşık bir edimdir. Buradan yola çıkarak, izleme pratiğinin genellikle ev içinde ve aile yaşamının rutin bir parçası olarak ortaya çıktığını akılda tutmak gerekir. Başka bir ifadeyle, televizyon izleyiciliğini gündelik hayatın dışında bir pratik olarak kavramlaştırmak zordur.

İzleyiciyi medya çalışmaları açısından anlamlı kılan iki nosyon olduğundan söz etmek mümkündür (Evans 1990). Bunlardan ilki, yukarıda da değinildiği gibi, izleyiciyi üretim ve medya metni arasındaki belirlenmiş konumundan kurtararak, onu bir özne olarak da "tanıyan" aktiflik nosyonudur. Anlam inşası etki araştırmalarının varsaydığı gibi yukarıdan aşağıya bir süreç olmadığı için, izleyici kendisi için kodlanmı̧ olan medya metnini, kendi anlam evreni içinde açımlayarak, başka bir ifadeyle yeniden inşa ederek, medya aracıllğıyla anlam inşası sürecine aktif bir biçimde dahil olur. Abercrombie ve Longhurst'ün de ifade ettikleri gibi, izleyicinin medya tarafindan sunulan ürünü özümsemediğini söylemekten ziyade, onunla ilişkilendiğini savunmak daha akla yakındır (1998). Medya metni yerine, metne kodlanmı̧ anlamlara odaklanmayı öneren bu yaklaşım izleyiciyi medya ne verirse onu kabul eden, pasif bir alıcı olarak gören bakışa bir tür alternatiftir. İzleme davranışının gerçekleşmesi, izlenen metnin olduğu gibi tüketildiği ve onaylandığı anlamına gelmez. Aktif izleyici nosyonu, izleyicilerin farklı amaçlar, hazlar ve yorumlarla medya metinlerine yaklaştığını ve bu sürecin basitçe bir tüketim süreci olmadığını, aksine, anlamın yeniden üretilmesi süreci olduğunu varsayar. Şüphesiz izleyicinin aktif bir biçimde iletişim sürecine dahil olmasını sağlayan, sahip olduğu farklı toplumsal özne konumlarıdır. Başka bir deyişle, izleyici medya metnini anlamlandırırken, örneğin, aynı anda bir kadın, bir Koreli, bir Budist, bir eşcinsel, bir orta sınıf mensubudur; dahası bunların toplamıdır. Medya metnini anlamlandırma süreci ise toplumsal kimlikleri, bireysel geçmişi, güncel toplumsal koşullar ve benzeri birçok değişkenin biraraya gelmesiyle oluşan çok katmanl, ilişkisel bir süreçtir. Aktif izleyici nosyonuyla yola çıkan izleyici araştırmaları, seçmeci bir yöntemle yukarıda sayılan değişkenlerin bir kısmını veya çalışmanın kapsamıyla doğru orantılı olarak mümkün olduğunca fazlasını hesaba katarak medya metninin nasıl anlamlandırıldığıyla, bu anlamlandırma sürecinin izleyicinin farklı toplumsal kimlikleriyle olan ilişkisine odaklanır. Diğer bir ifadeyle, izleyici televizyon programiyla ne yapar sorusunun sosyolojik, psikolojik ve/veya siyasal nedenleriyle ilgilenir. Silverstone’a göre, aktif izleyici nosyonu bir tür totolojidir (1994: 153). Çünkü televizyon izleme pratiği öyle veya böyle aktif bir süreçtir, dolayısıyla aktiflik nosyonuyla tam olarak neyin kast edildiğini belirgin bir biçimde tarif etmek önemlidir. Benzer bir yaklaşımla Takahashi, aktif-pasif dikotomisinin izleyici araştırmaları açısından bir tür açmaza işaret ettiğini belirtir ve aktif izleyici yerine "izleyici katılımı" (audience engagement) kavramını kullanmayı önerir (2009:7). Böylelikle televizyon düğmesini 
açıp kapatmaktan, program içeriği konusunda sosyal medyada yorum yapmaya kadar geniş bir etkinlik dizisi kapsanmış olur.

İzleyicinin çoklu kimliklerini tanımak, bizi izleyici kavramını mümkün kılan diğer nosyona götürür: Metin tarafindan kodlanan egemen anlama direnen izleyici nosyonu (Hall 1980; Morley 1980). Direnen izleyici nosyonu, kuşkusuz iki uç noktadan yaklaşıldığında boşa çıkar. Zira mutlak bir direnişle, izleme davranışının sürdürülmesi zordur. Medya metnine bütünüyle muhalif olan izleyici, büyük olasılıkla bir noktada izlemekten vazgeçecektir. Her şeyden önce medya metni bir çokluktur, birden fazla mesajı, fikri, temsili içeren karmaşık bir yapıdır. Bu nedenle izleyicinin neye direndiği sorusunun yanıtı oldukça muğlaktır. Diğer yandan, medya metni, kendi içinde türsel ve kategorik uylaşımları olan anlamlı bir bütün olmasına karşın, bütünüyle "tutarlı" ve "kapalı" olduğundan söz etmek güçtür. Medya metni, her metin gibi, boşlukları, çelişkileri, açıkları olan bir bütündür. Bu nedenle izleyicinin metnin bütünselliğine olduğu kadar, çelişkilerine nasıl yanıt verdiği, hangi çelişkileri görüp hangilerine gözünü kapadığ nıtları yoktur. Bu nedenle direnen izleyici nosyonuna oldukça titiz yaklaşmak gerekir. İzleyicinin direniş potansiyelini fetişleştirmeden, benzer bir mantıkla küçümsemeden veya yok saymadan, medya metinleri aracıllğıyla toplumsal anlamların nasıl inşa edildiği sorusuna anlamlı yanıtlar üretebilmek mümkündür. İzleyici iletişim sürecinin aktif bir bileşeni olarak görmek, medya metinlerini yorumlayarak eleştirebildiğini, reddedebildiğini veya dönüştürebildiğini kavramak izleyiciyi politik bir özne olarak medya çalışmalarına davet etmek anlamına gelir. Bu davetin aşağıda tartışılacağı üzere medya çalışmaları açısından oldukça verimli sonuçları olduğu söylenebilir.

\section{Fragmanlaşma ve Yakınsama/Yöndeşme: Yeni İzleyici Kültürlerine Doğru}

İzleyicilik, teknoloji-bağımlı bir konumdur. Başka bir ifadeyle, teknolojik gelişmeler izleyicilik konumunu ve pratiklerini dönüştürür. Günümüzde izleyicilik pratiklerini dönüştüren en önemli teknolojik gelişme internet teknolojileri ile birlikte televizyon yayıncılığı alanında ortaya çıkan değişimdir. Kanal sayısının artış1, tematik yayınc1lık, dijitalleşme ve ulusaşırılaşma gibi gelişmeler izleyiciyi, artık büyük bir grup olarak tarif edemeyeceğimizin altını çizerler (Webster 2005). İzleyicinin fragmanlaşması olarak kavramsallaştıran bu süreç, üç veya dört kanal seçeneği arasında sıkışmıs, dolayısıyla kitlesel olan izleyicinin, artan kanal ve yayın seçenekleriyle birlikte küçük gruplara bölünmesidir (Webster 1986). Bu anlamda fragmanlaşma olgusu ortak bir televizyon kültürünü kitlesel olarak tüketen "televizyon izleyicisi" kavramını da boşa çıkarıyor gibi

görünmektedir. Bunun yerine kanallar ve programlar etrafında öbekleşen daha 
dar bir televizyon izleyicisi tahayyülü ya da televizyon izleyicisi yerine "izleyici grupları" kavramsal açıdan daha sağlam bir zemini işaret eder.

Diğer yandan, izleyicinin küçük gruplara bölünerek fragmanlaştığ savunusu, televizyon aygitı yerine program düzeyinde düşünüldüğünde sorgulanmaya açıktır. Zira dizi veya reality show gibi ulusal yayın yapan kanallarda yayınlanmayan yapımlar internet aracıllğıyla ulusaşırı bir izleyici kitlesine ulaşabilir. Kitlesel ölçekte, izleyicileri aynı anda televizyon başında hayal edemesek de özellikle İngilizce konuşan ülkelerden dünyaya ulaşan yapımların hedeflenen kitlenin ötesinde izlendiğini söyleyebiliriz. Dolayısıyla ulusal sınırlar içinde düşündüğümüzde sayısal olarak küçük gruplara bölünmüş fakat küresel ölçekte genişlemiş bir izleyici grubunun varlığından söz etmek mümkündür.

Bugün internetle çeşitlenen teknolojik yenilikler izleyici kavramına farklı bir bakışla yaklaşmayı gerektiriyor. İzleyicilik deneyimini birçok açıdan dönüştüren bu gelişmelerin etkisi, üç noktadan ele alınabilir. Öncelikle farklı teknolojilerin birarada kullanılmasına olanak sağlayan gelişmeler, izleyiciyi televizyon ekranının karşısında otururken veya ev işleriyle uğraşırken çerçeveleyen resmi oldukça değiştirir. İzleyiciler programlara, izleme davranışının dışında, cep telefonu mesajlarıyla, fan sayfalarıyla, sosyal medya aracılığıyla, internet forumlarıyla oldukça çeşitli biçimlerde yanıt verebilir. Özellikle televizyon açısından özgül olan bir başka gelişme, televizyon için üretilen programların internette tüketilmesidir. Bu durum izleyici araştırmalarına belirli bir iletişim aracına odaklanarak yaklaşmayı oldukça problemli hale getirir. Zira karşınızda televizyonun kendine ait uylaşımlarına göre üretilen, ancak internet ortamına aktarıldığında yeniden formatlanan ve farklı biçimlerde tüketilen bir medya metni vardır. Programın yayınlanacağı zaman aralığına kafa yoran, programı reklam aralıklarına göre bölen, program akışını gözeterek yapımı önceki ve sonraki programlarla ilişkisel biçimde konumlandırma mantığı, internet ortamına transfer olduğunda bambaşka bir dile ve işleyişe göre yeniden biçimlenir ve konumlanır. Reklamlarla bölünen televizyon metni, web 2.0'ye aktarımı kolaylaştırmak ve izleyenin aygıtına yükleme hızını arttırmak bakımından çeşitli parçalara bölünebilir veya tek bir parça halinde izlenebilir. Televizyonun parçalı akışı internetin diline çevrildiğinde zamana ve hıza dair farklı konvansiyonlar ortaya çıkmış olur.

Diğer yandan internet ortamından televizyon programlarını izlemek, televizyon aygıtına hiç "bulaşmadan" da televizyon kültürünün bir parçası olmanızı olanaklı kılar. Bu durum, izleyici olarak daha bireysel, seçmeci bir tutum takınmanızı da kolaylaştırır. Karasal yayın yapan ulusal kanallarda izleyemeyeceğiniz dizileri ve reality programlarını internette takip etmeniz ve kendinize ait bir program "portföyü" oluşturmanız mümkündür. Dolayısıyla izleyiciliğin kolektif "doğasını" yer yer tahrip eden, yer yer de o kolektiviteyi farklı bir bi- 
çimde yeniden kuran yeni bir alan ortaya çıkar. Artık dün gece televizyonda izlediğiniz tartışma programını ertesi sabah işyerindeki arkadaşınızla tartışma beklentisiyle işe gittiğinizde, onun internete yeni "düşen" bir yabancı yapımın son bölümünü izlediğini öğrenmeniz daha olasıdır. Bu noktada televizyonu toplumsal bir aygit olarak hayatlarımıza iyice yerleştiren "televizyon muhabbeti” (tv talk) tek yönlü ve gerçek zamanlı olma özelliğini yitirir (Scannel 1991; Livingstone ve Lunt 1993; Gillespie 1995). İşyerindeki arkadaşınızı tartı̧̧ma programının ilginç olduğuna ikna edebilirseniz, akşam eve döndüğünde programı internet üzerinden izlemesi ve "televizyon muhabbeti" hevesinizin geç de olsa karşıllk bulması mümkündür. Televizyonun "şimdi ve burada" olma niteliği, video kayıt cihazlarıyla bir biçimde yitmişti. Bugün internet teknolojileriyle, "şimdi ve burada" olma niteliği o potansiyeli tam olarak gerçekleştirmeyecek olsa bile, "her zaman ve her yerde" olma potansiyeline evrilmiştir. Elbette, bu tür değişimlerin kapsamına temkinli yaklaşmak gerekir. Elektronik kitap teknolojisinin, öngörülenin aksine, kitap satışlarını arttırdığı gibi, farklı bir mecradan yayılma olanağının televizyonun popülaritesini arttırdığı, televizyon kültürünün internet mecrası üzerinden de akmaya başladığı söylenebilir. En azından televizyonla internetin kültürel olarak yakınsamasına neden olan, melez bir izleyici deneyiminden söz edilebilir. Nitekim bu melezleşme, popüler kültürün katıp karıştıran, üst üste bindiren, harmanlayan, sınırları flulaştıran, seçkin olanla sıradanı buluşturan tarzına da oldukça uygundur.

Dijital yayınc1lık teknolojisi televizyonun temelde "ulusal" a seslenen sınırlar1nı ulusaşırı bağlama doğru genişletmiştir (Gillespie 2000; Karim 2003; Georgiou 2013). Bu da bizi Silverstone'un yukarıda sözü edilen, televizyonun zaman ve mekan bağımlı oluşu vurgusuna geri götürür. Televizyon yayıncılığının ulusaşırı bir karakter kazanması, televizyonun yalnızca kültürlerarası değiş tokuş açısından etkili bir aygıt haline gelmesini sağlamaz. Aynı zamanda, toplumsal bağlamları farklı coğraflara taşımayı olanaklı kılar. Söz gelimi, göçmen kimliğinin televizyon aracilığıyla nasıl kurulduğu sorusu tam da bu noktada yeni bir boyut kazanır. Zira uydu yayıncılığından önce kendi göç ettikleri ülkenin medyası ve kendi yarattıkları yayıncılık mecraları üzerinden göçmen kimliğini deneyimleyenler, artık anavatanlarına ulusaşırı televizyon aracilığıyla da yaygın biçimde bağlanabilirler (Karim 2003; Georgiou 2013). Dolayısıyla dijital teknolojiler göçmen izleyicilik kimliğine de yeni bir boyut kazandırmış ve televizyon izleyiciliğini ulusaşırı kimlikler açısından da düşünme gerekliliğini doğurmuştur. Diğer yandan, televizyon kültürü açısından ulusaşırılaşma yurtdışında üretilen ürünlerin tüketilmesi açısından düşünüldüğünde, televizyonun çoğunlukla Batı'nın egemen olduğu bir mecraya dönüştüğü de vurgulanmalıdır. Dolayısıyla dijital yayıncılık ulusal sınırları aşmayı sağlasa da uluslararası eşitsizlikleri ortadan kaldırdığını söylemek mümkün değildir. 
Teknolojiik gelişmelerin izleme deneyiminde yarattığı zamansal ve uzamsal dönüşümün çapını çok da abartmamak gerekir. Zira medya metninin, öncelikli olarak hangi aygıt aracıllğıyla izleyiciye ulaşacağı, metnin biçimine ve içeriğine yönelik bir tercihi de içerir. Başka bir ifadeyle televizyon için üretilen bir program internet ortamına transfer olsa da televizyonun biçimsel özelliklerini büyük ölçüde taşımaya devam edecektir. Üretimin gerçekleştiği mecra ile ürünün tüketildiği mecra arasındaki fark, üretim mecrası lehine varlığını sürdürmektedir.

Dennis'e göre, yakınsama/yöndeşme öncelikle iletişimin bütün biçimlerinin bütünleşmesini sağlayan bir olgudur (2006: 23). Böylelikle geleneksel medya internet teknolojileri aracilığıyla birbirine bağlanmış ve bu süreci düzenleyici mekanizmaların yakınsaması ile genel anlamda medya ortamının kuralsızlaşması takip etmiştir. Yakınsama açısından önemli olan noktalardan biri de televizyon izleyicisinin televizyon dışındaki teknolojilerden de televizyon programlarını tüketebilmesinin yanında, "televizyon kültürü"nün televizyon dışı mecralarda akma olanağı bulmasıdır. Gray'e göre, yakınsama televizyon içeriğinin web sayfaları, oyunlar, kitaplar, t-shirtler, çantalar vb. tüketim maddeleri gibi, televizyon dışındaki alanlara "taşmasını" kolaylaştırmıştır. Bu durumda yakınsama sadece televizyon metnini alımlama/tüketme/izleme anını değil, o anın ötesine taşan bir televizyon kültürünü de belirler. Dolayısıyla izleyiciyi televizyon aygıtı dışındaki medya alanlarında da varlık gösteren televizyon kültürünün bir parçası olarak düşünmek gerekir.

Medyayı insanın algılarını, hislerini ve değerlerini belirleyen bir tür "açık sistem” olarak anlamayı öneren medya ekolojisi kavramı (Postman 2000), kavramın içerdiği teknolojik belirlenimci vurguya karşın, günümüzde çoklu medya ortamlarıyla çevrelenen izleyiciyi farklı biçimlerde yeniden düşünmemize olanak sağlayabilir. Yakınsayan medya, izleyiciyi sürekli birbirine gönderme yapan, birbirini yeniden üreten farklı teknolojilerle ilişkilendirir. Başka bir ifadeyle izleyici açısından söz konusu olan sadece birden fazla medya teknolojisiyle çevrelenmiş olmak ve bunları kullanmak değildir. İzleyici birbirine çeşitli ağlar ve mekanizmalarla bağlı olan ve zaman zaman iç içe geçen bir medya ağının içerisinde konumlanır. İzleyicinin aynı anda birden fazla aygıtla ilişkilenmesine neden olan, aygitların birbirlerinden devşirdikleri özelliklerle izleyiciye çoklu şekillerde hitap eden bu medya ekolojisi, izleyiciyi tek bir aygitla ilişkilendirerek teorize etmeyi de güçleştirir. Televizyon uydusu üzerinden radyo dinleyen, internetten televizyon programı izleyen izleyiciyi hangi aygita göre tarif edeceğimiz belirsizdir. İzleyiciyi teknolojiyi tüketen bir varlık olarak kavradığımızda ya da izleyiciyi tükettiği ürüne göre tarif ettiğimizde "neyin izleyicisi” sorusuna vereceğimiz yanıtlar farklılaşır. Eğer internetin "kullanıc1ları", televizyonun ise "izleyicileri" varsa, yakınsayan internet ve televizyon teknolojilerini kullananları nasıl tanımlayacağımız, hakikaten bağlamsal bir 
soru haline gelir, hem izleyici hem kullanıcı kavramı tek başına kullanıldığında boşa çıkabilir. Özetle, çoklu medya ekolojileri geleneksel olarak tarif edilen "televizyon izleyicisi" kavramına meydan okur. Bu meydan okuma izleyici ölçümlerini de dönüştürmektedir. Twitter başta olmak üzere, sosyal medya mecraları izleyici ölçümlerinin gerçekleştiği bir alan olarak karşımıza çıkar. Sosyal medyanın bireylerin tüketici profiliyle ilgili belirgin reklam veren kuruluşlara fikir vermesi, hangi programın hangi gelir, yaş, cinsiyet grubu tarafından takip edildiğini anlamayı kolaylaştırması geleneksel rating ölçüm sistemlerine olan bağımlılığı sarsmış görünmektedir. Reklam verenlerin özellikle kurmaca programları kullanarak sosyal medya üzerinden reklam yapması olgusu da bu duruma eşlik eder. Böylelikle televizyon izleyicisi yayıncılık ve reklam piyasası açısından internet mecrasında da takip edilebilen, tüketici olarak eğilimleri ve yönelimleri ölçülebilen bir birime dönüşmüş olur.

İçinde bulunduğumuz çoklu medya ortamını multimedya ekolojileri kavramıyla karşılamanın izleyici açısından iki yönlü bir durumu tarif ettiği söylenebilir. Öncelikle medya kültürünü giderek artan biçimde farklı araçlar (medium) aracıllğıyla ve teknolojik yakınsama sayesinde aynı anda birden fazla araçla deneyimlendiği, dahası, yeni kuşaklar için medya kültürü, içine doğdukları yaşamın, toplumsal yapının "adeta" doğal bir parçası gibi işlediği söylenebilir. Başka bir ifadeyle, yeni kuşaklar çoklu medyayla çevrelenmiş bir hayata doğdukları için, bu araçlar dünyası, adeta bir "doğal alan”a, kelimenin ikinci anlamıyla da bir tür ekolojiye karşılık gelir. Diğer taraftan medyaya ekolojik bir sistem olarak yaklaşmanın, multimedya ortam içerisindeki eşitsizlikleri ve güç ilişkilerini "doğallaştırma" riski taşıdığını vurgulamak gerekir. Bu nedenle çoklumedya ekolojileri içinde izleyicinin değişen konumuna odaklanmak oldukça önemli. Medya ekolojilerinde güç ilişkileri bağlamında izleyicinin konumu iki açıdan ele alınabilir. Birincisi izleyicinin bağlamsal olarak "yaratıcı", üretici ve kullanıcı olarak birden fazla konumu da içerebilecek biçimde yeniden tarif edilmesi konusudur. Örneğin, fan gruplarında izleyiciyle yapımcılar arasında özellikle forumlar ve buluşma günleri üzerinden kurulan yakın bağlar, geri besleme, izleyicinin görüş ve önerileri çerçevesinde senaryo, sanat yönetmenliği, oyuncu seçimi gibi kimi konularda yapılan değişikliklerle, izleyicinin kolektif bir "özne” olarak üretim sürecine dahil olduğu söylenebilir. Ancak Jenkins'in de vurguladığı gibi, yakınsama sayesinde gerçekleşen izleyici-üretici etkileşimine temkinli yaklaşmak gerekir (2014: 279). Çünkü izleyicinin geri bildirimlerle medya içeriğine müdahale edebilme kapasitesi medya üreticilerinin kurumsal gücü tarafından kolaylıkla manipüle edilebilir. Etkileşim belirli teknolojilere içkin bir özellik olarak tasarlandığı için medya üreticilerinin kontrolü dahilinde gerçekleşmesi hayli kuvvetli bir olasılıktır (2014: 283). Diğer taraftan parodisi yapilan popüler dizi sahneleri ve yeniden canlandırmalar, televizyon metnini aktif olarak yeniden yazan ve esas metinle 
ilişkilendirerek dolaşıma sokan bir izleyicilik deneyiminin de yaygınlaştığını işaret eder. Güç ilişkileri bağlamında ikinci mesele tam da bu noktada ortaya çıar. Medya teknolojilerine erişim olanakları, dijital okuryazarlık, medyayı yakınsayan işlevleriyle birlikte kullanabilme gibi başlıklarda belirginleşen "izleyicinin ekolojik sermayesi” olarak tarif edebileceğimiz, hem ekonomik hem kültürel bir varsıllığa tekabül eden farklılık, izleyicinin çoklu medya ekolojisindeki konumunun "yaratıcı", üretici ve kullanıcı olarak ne ölçüde tarif edilebileceğinin sınırlarını çizer. Bu bağlamda multimedya ekolojilerinde "yaşayan" izleyiciyi, olanak, kabiliyet ve alışkanlıklar bakımından izleyiciler içinde görece daha küçük bir grup olarak tarif etmek daha uygun görünmektedir.

Akıllı telefon, tablet, dizüstü bilgisayar, televizyon ve radyoyu aynı sepete koyup ilişkisel biçimde tarif etmemize olanak veren internet teknolojisi, yine bir üst başlık olarak izleyiciyi niteleyebilir. Fakat burada da farklı aygitlarda ortaya çıkan farklı ve çapraz kullanım biçimlerini bağlamsal olarak ortaya koymak gerekecektir. Dolayısıyla, tarif etmeye çalıştı̆̆ımız her iki biçimde de çoklu medya ortamındaki izleyicidir. Yeni eklemlenmelerle genişlemeye devam etmesi muhtemel medya ekolojilerinde -medya ekolojilerini açık bir sistem olarak düşünmemizin nedenlerinden biri de budur- izleyici, her yeni aygit veya teknolojiyle yeniden ele almamı gereken bir kavram olabilir. Medyayla ve medya metinleriyle ilişkilenme biçimlerinin dönüşmesi, izleyiciyi de en az teknoloji kadar dinamik bir kavram olarak düşünmemiz gerektiğini işaret eder. Kaldı ki izleyici sadece medya metni veya aygıt karşısındaki konumuna göre değil, kendisi gibi diğer izleyicilerle geliştirdiği sosyal etkileşimle de tarif ettiğimiz bir kavramdır. Bu açıdan çoklu medya ortamındaki izleyici, oturma odasındaki televizyonun başındaki izleyiciden oldukça farklı bir konumdadır. Televizyon izleyiciliğinin bilgisayar, tablet, telefon gibi aygitlara kayması daha sosyal bir izleyicilik pratiğinden, daha yalıtılmış bir izleyiciliğe kayışı da işaret ediyor olabilir. Başka bir ifadeyle gündelik ortamda aile ilişkileriyle çerçevelenmiş bir televizyon izleme davranışının internet ile birlikte daha bireysel ve sosyal olarak yalıtılmış bir biçimde gerçekleşme olasılığı yüksektir. Zira çoklu medya ortamında kolektif hareket edebilmek daha güçtür.

Yukarıda tartış1lan birçok gelişmeyi, özellikle internet teknolojisine eşitsiz erişim koşulları açısından düşündüğümüzde, bölgesel farklılıkları göz önüne almanın zorunlu olduğu açıktır. Örneğin, dünya nüfusunun \%50'den azı internete erişim olanaklarına sahiptir ve bu oran Kuzey Amerika ve Avrupa gibi internete erişim oranının \%80'i bulduğu ve aştığı bölgelerle, Afrika gibi \%25’lerde seyrettiği bölgeler arasındaki derin uçurumla birlikte değerlendirilmelidir. ${ }^{2} \mathrm{Bu}$ nedenle fragmanlaşma, yakınsama, çoklu medya ekolojileri gibi internet odaklı, 
farklı sahiplik ve erişim olanaklarıla belirlenen bir alanda televizyon izleyicisini, bölgesel ve yerel farklılıkları da hesaba katarak yeniden düşünmek gerekir.

\section{Sonuç}

Televizyon izleyiciliği artık yalnızca belirli bir etkinliğin, yani televizyon izleme davranışının, ötesine geçmiş bir "pratik"tir. Dolayısıyla yakın dönemdeki izleyici araştırmalarının belirli bir programı izleyenlere odaklanmak yerine, izleyiciyi çevreleyen medya kültürünü kavramaya çalıştıklarını görürüz (Alasuutari 1999: 6). Elbette bu durum geniş bir bağlam içinde izleyiciyi yitirmek anlamına da gelebilir. Zira televizyon üretiminin doğası, hem üretilen metnin hem de izleyicilik pratiklerinin belirli uylaşımlar çerçevesinde gerçekleşmesini gerektirir. Dolayısıyla izleyici araştırmaları söz konusu olduğunda, televizyonun gerekleri ve getirdikleriyle televizyonu çevreleyen çoklu medya ortamı ve daha geniş toplumsal bağlam arasında ince bir denge tutturmak, yani hem televizyon içre hem de televizyonu aşkın bir bakış kurmak gerekir. Başka bir ifadeyle, izleyici araştırmaları açısından televizyonun neliğini unutmadan onu medya-aşırı bir bağlamda kavramak artık elzemdir (Evans 2011; Simons 2014).

Yakınsamanın önemli sonuçlarından biri, televizyona ait uylaşımların internet mecrasına taşınması, özellikle Netflix gibi platformlarda izleyici ve kullanıcı konumlarının iç içe geçtiği pratiklerin ortaya çıkmasıdır. Bu bağlamda çoklu medya ortamlarının izleyici alışkanlıklarını değiştiren dolaylı etkilerinden de söz etmek gerekir. Diğer medya ortamlarında kazanılan deneyimlerden ve hazlardan bağımsız televizyon izleyicisini hayal etmek giderek güçleşmektedir. Yakınsamayla ortaya çıkan izleyicilik haz ve deneyimlerinin giderek bireyselleştiğini de vurgulamak gerekir. Bununla kast edilen kişiye özel program listelerinin oluşturulabilmesi ve dijital yayıncılı̆̆ın kişinin izlediklerinden yola çıkarak önerilerde bulunabilmesi olduğu kadar, izleyicinin ulus-aile-tüketici üçlemesi dışında kişisel beğenilerle kurulan bir ağa, sanal bir kolektiviteye de dönüşebilmiş olmasıdır. Bu kolektivitenin nasıl tarif edildiği sorusu da, izleyici araştırmaları açısından oldukça vaat edici bir alan açmaktadır.

Türkiye bağlamında düşünüldüğünde, izleyici çalışmalarının verimli bir alan olduğu söylenebilir. Yukarıda tartışılan bütün sorularla birlikte Türkiye'de izleyici büyük ölçüde tarihsel, kültürel, yerel ve ulusaşırı düzeylerde araştırılmayı bekleyen bir muğlaklıktır. Yeni ve güncel araştırma konuları sıralanacak olursa uzun ve ilginç bir liste ortaya çıkar. Örneğin, televizyon ve kültürel bellek açısından Türkiye'de ilk televizyon izleyiciliği deneyimlerini araştırmak için henüz geç değildir. Bu dönemi canlı bir biçimde hatırlayan kuşaklar hâlâ hayattadır. Benzer bir tarihsel çalışma, TRT INT'le başlayan ulusaşırı izleyicilik sürecini Avrupa'da yaşayan Türkiyeli göçmenlerle ele alabilir. Yerel kimlikler ve yerel televizyon izleyiciliği, Kürtçe ve başka dillerde yayın yapan kanalların, 
izleyicilerin kültürel kimliği açısından ne anlam ifade ettiği, televizyon izleyiciliğini internet mecrası üzerinden gerçekleştirme süreci, kurumsal ve aile içi denetim bağlamında çocuk izleyiciler, dijital platformlarda izleyici alışkanları ve benzeri çalı̧̧ma önerilerini çeşitlendirmek mümkündür. İzleyici araştırmaları, özellikle Türkiye bağlamı düşünüldüğünde vaat edici bir çalışma alanı olarak daha fazla sayıda araştırmacının ilgisini beklemektedir.

\section{Kaynaklar}

Abercrombie, Nicholas ve Brian Longhurst (1998). Audiences: A Sociological Theory of Performance and Imagination, London: Sage.

Alasuutari, Pertti (1999). Rethinking the Media Audience, London: Sage.

Ang, Ien (1985). Watching Dallas: Soap Opera and the Melodramatic Imagination, New York: Methuen.

- (1991). Desperately Seeking the Audience, London: Routledge.

Arun, Özgür (2015). "Kültürel Hepçiller: Ne Seçkin Ne Sıradan, Sadece Olağan! Türkiye Televizyonunda İzleyici Beğenilerinin Analizi”, Toplum ve Bilim 133, s.247-280.

Batmaz, Veysel ve Asu Aksoy (1995). Türkiye'de Televizyon ve Aile, Ankara: Başbakanlık Aile Araştırma Kurumu.

Binark, Mutlu (1995). “Ben Bir Kadın Özne ve Benim Sabun Köpüklerim”, Ankara Üniversitesi İletişsim Fakültesi Yıllığı, Ankara: Ankara Üniversitesi.

Blumler, Jay G. ve Elihu Katz (1974). The Uses of Mass Communication, Newbury Park: Sage.

Couldry, Nick (2011). "More Sociology, More Culture, More Politics, or, a Modest Proposal for 'Convergence' Studies”, Cultural Studies 25/4-5, s.487-501.

Dennis, Everett.E. (2006). “Television Convergence Conundrum”, Television Quarterly 37/1, s.22-26.

Evans, William A. (1990). "The Interpretive Turn in Media Research Innovation, Iteration, or Illusion?”, Critical Studies in Mass Communication 7/2, s.147-168.

Evans, Elizabeth (2011). Transmedia Television: Audiences, New Media, and Daily Life, New York: Routledge.

Fiske, John (1987). Television Culture, London: Routledge.

Fiske, John ve John Hartley (2003). Reading Television, London: Routledge.

Gerbner, George (1998). "Cultivation Analysis: An Overview", Mass Communication E Society 1/3-4), s.175-194.

Georgiou, Myria (2013). "Seeking Ontological Security Beyond the Nation: The Role of Transnational Television", Television ENerw Media 14/4, s.304-321.

Gillespie, Marie (1995). Television, Ethnicity and Cultural Change, London: Routledge. 
- (2000). "Transnational Communications and Diaspora Communities", Ethnic Minorities and Media: Changing Cultural Boundaries, Der. Simon Cottle, Berkshire: Open University Press.

Gray, Jonathan (2008). Television Entertainment, London: Routledge.

Gülnar, Birol ve Şükrü Balcı (2010). "Yabancı Uyruklu Üniversite Öğrencileri Arasında Kültürleşme ve Televizyon İzleme Motivasyonları”, Türkiyat Araştırmaları Enstitüsü Dergisi 28, s.447-484.

Hall, Stuart (1980). "Encoding/Decoding”, Culture, Media, Language, Der. Stuart Hall, Dorothy Hobson, Andrew Lowe ve Paul Willis, London: Hutchinson.

Jenkins, Henry (2014). "Rethinking 'Rethinking Covergence/Culture”, Cultural Studies 28/2, s.267-297.

Karim, Karim H. (2003). The Media of the Diaspora, London: Routledge.

Katz, Elihu ve Paul Lazarsfeld (1955). Personal Influence: The Part Played by People in the Flow of Mass Communications, Glencoe: The Free Press.

Livingstone, Sonia ve Peter Lunt (1993). Talk on Television: Audience Participation and Public Debate, London: Routledge.

McQuail, Denis ve Sven Windahl (2010). İletişim Modelleri, Çev. Konca Yumlu, Ankara: İmge.

Morley, David (1980). The Nationwide Audience: Structure and Decoding, London: British Film Institute.

- (1992). Television, Audiences and Cultural Studies, London, Routledge. Nightingale, Virginia ve Karen Ross (2003). Critical Readings: Media and Audiences, Berkshire: Open University Press.

Özçetin, Burak (2010). “Kullanımlar ve Doyumlar'dan İzlerkitle Sosyolojisine: Türkiye'de İzlerkitle Çalışmaları”, İletişim Araştırmaları 8/2, s.9-37.

Özer, Ömer (2005). "Yetiştirme Kuramı: Televizyonla Yaşamanın İdeolojik Kültürel Sonuçlarına Yönelik Yapılan Araştırma”, Anadolu Üniversitesi Sosyal Bilimler Dergisi 5/1, s.75-108.

Özsoy, Aydan (2011). Televizyon ve İzleyici: Türkiye'de Dönüşen Televizyon Kültürü ve İzleyici, Ankara: Ütopya.

Postman, Neil (2000). "The Humanism of Media Ecology", <http://media- ecology.org/ publications/MEA_proceedings/v1/humanism_of_media_ecology. html>

Ruddock, Andy (2001). Understanding Audiences: Theory and Method, London: Sage. Scannel, Paddy (1989). "Public Service Broadcasting: History of a Concept", Understanding Television, Der. Andrew Goodwin ve Garry Whannel, London: Routledge.

- (1991). Broadcast Talk, London: Sage.

Silverstone, Roger (1994). Television and Everyday Life, London: Routledge. 
Simons, Nele (2014). "Audience Reception of Cross- and Transmedia TV Drama in the Age of Convergence", International Journal of Communication 8, s.22202239.

Takahashi, Toshie (2009). Audience Studies: A Japanese Perspective, London: Routledge.

Türkoğlu, Nurçay (2010). "Toplumsal Dönüşümler ve Medyada İzleyici Katılımı”, Ankara: Tübitak Raporu.

Webster, James G. (1986). "Audience Behavior in the New Media Environment", Journal of Communication 36/3, s.77-91.

— (2005). "Beneath the Veneer of Fragmentation: Television Audience Polarization in a Multichannel World", Journal of Communication 55/2, s.366-382. 


\begin{abstract}
Who is Television Audience? A Conceptual Discussion

"Audience" is a vague concept which is difficult to define from the perspective of television studies. Various epistemological approaches within the field of communication define audience and the processes of communication in different ways. Fundamentally, the answer of who the audience is lays in the ways in which the viewing practice is understood. Television viewing practices are situated within the everyday social interaction. In this context, different ways of social interaction which emerge through new technologies shape television viewing practices to a certain extent. In this article, the conceptual evaluation of the audience in television studies, the changes in viewing practices with contemporary technologies and what this change brought to the field of television studies is discussed.
\end{abstract}

Keywords: Television, audience, audience studies, convergence, fragmentation 
